Article

\title{
How to Implement Safe, Efficient and Cost-Effective SARS-CoV-2 Testing in Urban and Rural Schools within One Month
}

\author{
Parastoo Kheiroddin ${ }^{1,+}+\mathbb{1}$, Magdalena Gründl ${ }^{2,+}{ }^{+}$, Michael Althammer ${ }^{1,+}{ }^{+}$, Patricia Schöberl ${ }^{1,3}$, Linda Plail ${ }^{3}$, \\ Ezgi Cibali ${ }^{4}$, Kristina Schraml ${ }^{5}$, Josef Scheiber ${ }^{5}$, Claudia Kiesewetter ${ }^{6}$, Andreas Kneissler ${ }^{6}$, Christopher Bartl ${ }^{7}$, \\ Daniel Wallerstorfer ${ }^{7}$, Julien-Tyron Barth ${ }^{8}$, Shabnam Rajabi ${ }^{8}$, Cornelius Roth ${ }^{8}$, Andreea Matei ${ }^{8}$, Christin Fetz ${ }^{8}$, \\ Heike Buntrock-Döpke ${ }^{1,3}$, Susanne Gastiger ${ }^{9}$, Mona Bodenschatz ${ }^{9}$, Maike Konrad ${ }^{9}$, Jakob Niggel ${ }^{10}$, \\ Philipp Pagel ${ }^{10}$, Guido Judex ${ }^{11}$, Michael Hubmann ${ }^{12}$, Catherine M. Sweeney-Reed ${ }^{13} \mathbb{1}$, Andreas Ambrosch ${ }^{4}$, \\ Thomas Wagner ${ }^{14}$, Andreas Burkovski ${ }^{9}$ (i) and Michael Kabesch ${ }^{1,3, *}$
}

check for updates

Citation: Kheiroddin, P.; Gründl, M.; Althammer, M.; Schöberl, P.; Plail, L.; Cibali, E.; Schraml, K.; Scheiber, J.; Kiesewetter, C.; Kneissler, A.; et al. How to Implement Safe, Efficient and Cost-Effective SARS-CoV-2 Testing in Urban and Rural Schools within One Month. COVID 2021, 1, 717-727. https://doi.org/10.3390/ covid1040057

Academic Editor: Roger Frutos

Received: 27 September 2021

Accepted: 17 November 2021

Published: 30 November 2021

Publisher's Note: MDPI stays neutral with regard to jurisdictional claims in published maps and institutional affiliations.

Copyright: (c) 2021 by the authors. Licensee MDPI, Basel, Switzerland. This article is an open access article distributed under the terms and conditions of the Creative Commons Attribution (CC BY) license (https:// creativecommons.org/licenses/by/ $4.0 /)$.
1 Department of Pediatric Pneumology and Allergy, University Children's Hospital Regensburg (KUNO), Hospital St. Hedwig of the Order of St. John, University of Regensburg, 93049 Regensburg, Germany; Parastoo.Kheiroddin@klinik.uni-regensburg.de (P.K.); michi.althammer1998@gmail.com (M.A.); Patricia.Schoeberl@barmherzige-regensburg.de (P.S.);

Heike.Buntrock-Doepke@barmherzige-regensburg.de (H.B.-D.)

2 Public Health Institute Cham, 93413 Cham, Germany; Magdalena.Gruendl@stmgp.bayern.de

3 Science and Innovation Campus Regensburg (WECARE), Hospital St. Hedwig of the Order of St. John, 93049 Regensburg, Germany; Linda.Plail@barmherzige-regensburg.de

4 Institute of Laboratory Medicine, Microbiology and Hygiene, Hospital of the Order of St. John, 93049 Regensburg, Germany; Ezgi.Cibali@barmherzige-regensburg.de (E.C.);

Andreas.Ambrosch@barmherzige-regensburg.de (A.A.)

5 BioVariance GmbH Diagnostics, 95652 Waldsassen, Germany; kristina.schraml@biovariance.com (K.S.); josef.scheiber@biovariance.com (J.S.)

6 Labor Kneissler GmbH \& Co KG, 93133 Burglengenfeld, Germany; Claudia.Kiesewetter@labor-kneissler.de (C.K.); Andreas.Kneissler@labor-kneissler.de (A.K.)

7 NOVOGENIA Limited, 5301 Eugendorf, Austria; christopher.bartl@novogenia.com (C.B.); daniel.wallerstorfer@novogenia.com (D.W.)

8 DATEV eG, 90429 Nuremberg, Germany; Julien-Tyron.Barth@DATEV.de (J.-T.B.); Shabnam.Rajabi@DATEV.de (S.R.); Cornelius.roth@DATEV.de (C.R.); Andrees.Matei@DATEV.de (A.M.); Christin.Fetz@DATEV.de (C.F.)

9 Department of Biology, Microbiology Division, Friedrich-Alexander-University Erlangen-Nuremberg, 91054 Erlangen, Germany; susanne.gastiger@fau.de (S.G.); mona.bodenschatz@fau.de (M.B.); maike.konrad@fau.de (M.K.); andreas.burkovski@fau.de (A.B.)

10 Maganamed Limited, 93053 Regensburg, Germany; jakob.niggel@maganamed.com (J.N.); philipp.pagel@maganamed.com (P.P.)

11 Pediatric Office Judex, 93049 Regensburg, Germany; gjudex@web.de

12 Pediatric Office Hubmann, 90513 Zirndorf, Germany; dr.hubmann@me.com

13 Department of Neurology, Center for Behavioral Brain Sciences, Otto von Guericke University Magdeburg, 39106 Magdeburg, Germany; catherine.sweeney-reed@med.ovgu.de

14 Intego GmbH, 91058 Erlangen, Germany; thomas.wagner@intego.de

* Correspondence: michael.kabesch@barmherzige-regensburg.de;

Tel.: +49-941-369-5801; Fax: +49-941-369-5802

+ Contributed equally.

Abstract: (1) Background: With vaccination and new variants of SARS-CoV-2 on the horizon, efficient testing in schools may enable prevention of mass infection outbreaks, keeping schools safe places and buying time until decisions on feasibility and the necessity of vaccination in children and youth are made. We established, in the course of the WICOVIR (Where Is the COrona VIRus) study, that garglebased pool-PCR testing offers a feasible, efficient, and safe testing system for schools in Germany when applied by central university laboratories. (2) Objectives: We evaluated whether this approach can be implemented in different rural and urban settings. (3) Methods: We assessed the arrangements required for successful implementation of the WICOVIR approach in a variety of settings in terms of transport logistics, data transfer and pre-existing laboratory set-up, as well as the time required to establish the set-up. (4) Results: We found that once regulatory issues have been overcome, all 
challenges pertaining to logistics, data transfer, and laboratory testing on different platforms can be solved within one month. Pooling and depooling of samples down to the individual test result were achievable within one working day in all settings. Local involvement of the community and decentralized set-ups were keys for success. (5) Conclusion: The WICOVIR gargle-based pool-PCR system is so robust and simple that it can be implemented within one month in all settings now or in future pandemics.

Keywords: school testing; monitoring; surveillance; SARS-CoV-2; COVID-19; gargle; pool-PCR; children; rural; urban; implementation

\section{Introduction}

School-based testing has become an important concept for keeping children safe at school during the Coronavirus disease (COVID-19) pandemic, especially as provision of vaccination to children is associated with considerable delay [1]. Antigen tests have been used widely to test adults for severe acute respiratory virus (SARS-CoV-2), and they have also been introduced into schools, with children performing the test themselves in classrooms. Recent data show that antigen tests cannot reliably detect new SARS-CoV-2 infections at an early stage [2,3], and that testing in the school environment is also cumbersome $[4,5]$. We and others have shown that gargle-based pool Polymerase Chain Reaction (PCR testing can provide a safe, efficient, and cost-effective alternative, [6-9] and thus the WICOVIR (Where Is the COrona VIRus?) study was initiated in March 2021 in the south of Germany [10].

Previously, we had gained experience in a proof-of-concept study, which began in the summer of 2020, of how testing of school children can be established successfully in selected urban schools [6]. Implementation of a PCR-based test system in rural regions was perceived as a major challenge or even obstacle for a broad, countrywide rollout. Here we provide evidence that the WICOVIR concept, which is based on gargle-based pool PCR testing, can be successfully implemented in a grassroots-approach in rural and urban counties within four weeks.

\section{Materials and Methods}

The WICOVIR project was designed in January 2021, approved by the ethics committee of the University of Regensburg in March 2021 (file number 21-2240_2-101), proposed to the Bavarian State Ministry of Health in February, and funded at the end of March 2021. All study procedures and protocols are available online (www.we-care.de/wicovir) and have been published in detail elsewhere [10]. Here we present findings following the implementation of the test system in four different Bavarian counties (Figure 1).

\subsection{Local and Regional SARS-CoV-2 Testing Setup}

For the county of Cham, Novogenia performed pool tests and the hospital laboratory in Regensburg performed depooling. In the Novogenia $\mathrm{GmbH}$ laboratory in Eugendorf/Salzburg, ribonucleic acid (RNA) was extracted using the MagnifiQ ${ }^{\mathrm{TM}}$ RNA buffer kit (A\&A Biotechnology, Gdansk, Poland) using an Auto-Pure96 Nucleic Acid Purification System (Hangzhou Allsheng Instruments, Shanghai, China) according to the manufacturer's protocol. Realtime (RT)-PCR-based SARS-CoV-2 RNA detection was performed using a Quantstudio 5 Real-Time PCR System (Thermo Fischer Scientific, Waltham, MA, USA) using the single-well dual target (open reading frame (ORF)1ab and nucleocapsid (N) gene) Fast Track Diagnostics (FTD) SARS-CoV-2 assay using a total volume of $10 \mu \mathrm{L}$ for the reaction according to the manufacturer's instructions. For depooling, samples were sent to Regensburg once a positive pool was identified by Novogenia. Depooling was performed as part of the study protocol either with the one-step RT-qPCR with the LightCycler ${ }^{\circledR}$ Multiplex RNA Virus Master (target E gene) using a Light Cycler 480 II Instrument (Roche 
Diagnostics, Mannheim, Germany) using a GeneXpert instrument (Cepheid, Sunnyvale, CA, USA).

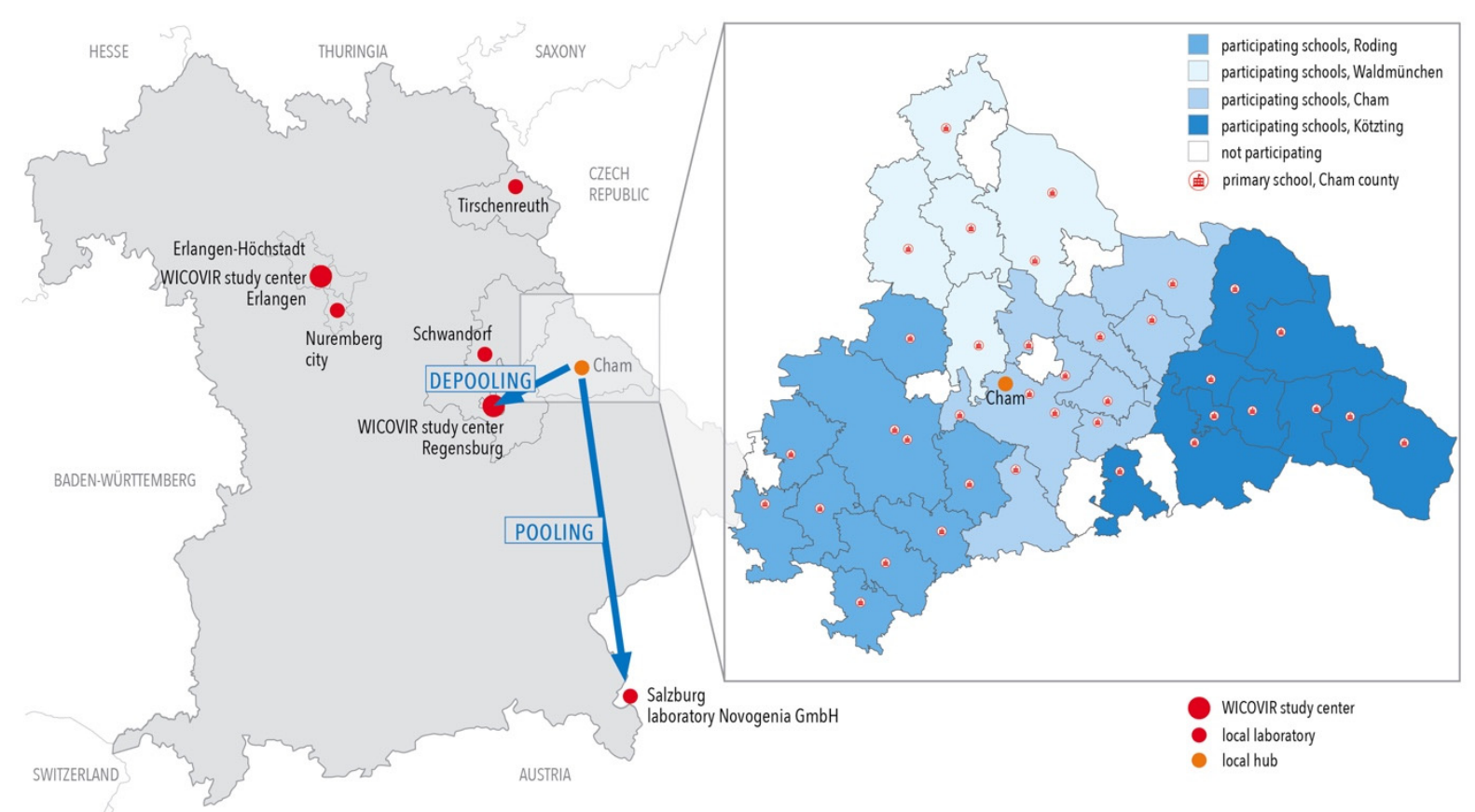

Figure 1. Map of participating counties of Eastern Bavaria and location of test centers. Map of participating counties of Bavaria. A zoom-in of the county of Cham exemplifies test-center and school locations and organization of routes in sectors for collecting samples. For Cham, pools were transported to the test center in Eugendorf near Salzburg, Austria, and for depooling to the test center in Regensburg, Bavaria, in the beginning of the project. In all other counties, local test centers were used or established within the county.

For the county of Schwandorf, the Kneissler laboratory in Burglengenfeld performed pool testing and depooling. RNA was extracted using the foodproof Magnetic Preparation Kit VI (Biotecon, Potsdam, Germany) using either an AutoPure96 Nucleic Acid Purification System (Hangzhou Allsheng Instruments, Shanghai, China) or a RoboPrep96 (Biotecon, Potsdam, Germany), according to the manufacturer's instructions. The RT-PCR was performed using the SARS-CoV-2 Complete Kit (Kylt, Emstek, Germany) using either a LightCycler96 (Roche, Basel, Switzerland), Stratagene Mx3005p (Agilent Technologies, Santa Clara, CA, USA) or an AriaMx Cycler (Agilent Technologies, Santa Clara, CA, USA), according to the manufacturer's instructions. The detection was based on a single well, dual target assay, which detects the $\mathrm{N}$ - and S-genes of the SARS-CoV-2 virus.

For Tirschenreuth county, the Scheiber laboratory, located within the county in Waldsassen, performed pool-PCR and depoooling. RNA was extracted using the EchoLUTION Viral RNA/DNA Swab Kit (BioECHO, Cologne, Germany) according to the manufacturer's protocol. RT-PCR-based SARS-CoV-2-RNA detection was performed using a CXF 96 or CFX Opus 96 (BioRad, Munich, Germany) using the VirQ Rapid SARS-CoV-2 kit, targeting the RNA-dependent RNA polymerase (RdRP) and envelope (E)genes (BAG Diagnostics, Lich, Germany) in a total volume of $20 \mu \mathrm{L}$ according to the manufacturer's instruction.

For the city of Nuremberg, the DATEV laboratory, located in the city itself, performed pool-PCR and depooling. Sputolysis of the pooled samples was achieved by addition of ascorbic acid to produce a final concentration of $62.5 \mathrm{mM}$ (Roth, Karlsruhe, Germany). Afterwards, an $18 \mu \mathrm{L}$ aliquot of the pool was mixed with $2 \mu \mathrm{L}$ of TCEP (Tris(2carboxyethyl)phosphine hydrochloride ( $25 \mathrm{mM}$, Sigma-Aldrich, Munich, Germany)) and heated at $95{ }^{\circ} \mathrm{C}$ for $5 \mathrm{~min} .2 \mu \mathrm{L}$ of the inactivated sample were added to the PCR reaction mix (10 $\mu \mathrm{L}$ of $2 \times$ Luna Probe One-Step Reaction Mix (New England Biolabs (NEB), Frankfurt/Main, Germany), $1 \mu \mathrm{L}$ of $20 \times$ Luna Warm Start RT Enzyme Mix (NEB), $1.5 \mu \mathrm{L}$ 
Primer/Probe Set (Integrated DNA Technologies), $0.5 \mu \mathrm{L}$ UDG (NEB), and $5 \mu \mathrm{L}$ RNase-free H20). The samples were then transferred into a MIC PCR Cycler (Biozym Scientific GmbH, Hess. Oldendorf, Germany), running the RT-PCR program of $55^{\circ} \mathrm{C}$ for $15 \mathrm{~min}$, followed by $95^{\circ} \mathrm{C}$ for $2 \mathrm{~min}$, and finishing with 45 cycles of $95^{\circ} \mathrm{C}$ for $10 \mathrm{~s}$ and $55^{\circ} \mathrm{C}$ for $45 \mathrm{~s}$.

For all locations except Regensburg, depooling was not necessary during the reported period of time but would have been performed according to the standard operating procedures of established, clinically accredited routine laboratories, determined by the respective public health officers.

\subsection{Ring Experiments}

To investigate whether existing equipment and test-setups in each laboratory could all be used successfully for detection of positive gargle-based pools and provide comparable results, a ring experiment with blinded samples of predetermined positive and negative gargle-based pool samples was designed. Samples were delivered to the laboratories $24 \mathrm{~h}$ after a positive pool was initially detected, and ring testing sample work-up and PCR were performed $48 \mathrm{~h}$ after gargling in all laboratories on the same day.

\subsection{Data Management}

Commercial and routine laboratories in this study used internationally recognized standards such as Health Level 7 (HL7) and lab data transfer (LDT) as well as custom comma separated value (CSV) tables for data transfer. The WICOVIR software was implemented in Javascript (frontend) and typescript (backend), respectively. Data were stored on a PostgreSQL relational database management system. The database and application were hosted at an ISO27001 certified data center in Germany. Encrypted back-ups were generated several times per day and stored off-site in a separate data center of another host provider in Germany. A general data protection regulation (GDPR)-compliant data protection concept was implemented and approved by the data protection officer in charge.

\section{Results}

\subsection{General Study Set-Up, Logistics, and Laboratory Testing}

After receiving ethical approval, a positive funding decision, clearance of data protection issues, and the approval of the Ministry of Education to perform tests in the schools within this project, we established a website to enable broad communication of studyrelated issues to the public. We also set up weekly webinars for the heads of the school to transfer information necessary for implementation of the testing program in local schools in an efficient and timely manner. Beyond the initial study areas in Regensburg and Erlangen, three counties and one city area decided to participate in the early phase of the project (Table 1).

For these counties and city, we offered local events to promote the study procedures to school directors and local authorities on-site. In the rural counties, a regional organizational team, which usually included the school board, the local health officer, and the county authority), was established in a timely manner. Our central study team supported the regional teams in the ordering of equipment and training of teachers. Local teams organized transport of samples from schools to the laboratories involved. Participating laboratories adapted study procedures to their pre-existing, standard set-up and performed confirmation tests (Table 2). 
Table 1. Characteristics of the four study regions.

\begin{tabular}{|c|c|c|c|c|}
\hline County/City Name & Cham & Schwandorf & Tirschenreuth & Nuremberg \\
\hline Inhabitants * & 128.094 & 148.477 & 71.696 & 515.543 \\
\hline $\begin{array}{c}\text { County/City area * } \\
\text { Set-up }\end{array}$ & $1.527 \mathrm{~km}^{2}$ & $1.458 \mathrm{~km}^{2}$ & $1.084 \mathrm{~km}^{2}$ & $186 \mathrm{~km}^{2}$ \\
\hline Decision to participate & 14.03 .21 & 23.03.2021 & 07.05.2021 & 08.03 .2021 \\
\hline \multicolumn{5}{|l|}{$\underline{\text { Schools }}$} \\
\hline Number of schools & 38 & 4 & 8 & 13 \\
\hline Forms of schools & All primary schools & $\begin{array}{l}\text { Selection of schools } \\
\text { from among all } \\
\text { school forms }\end{array}$ & $\begin{array}{l}\text { Selection of schools } \\
\text { from among all } \\
\text { school forms }\end{array}$ & All interested schools \\
\hline \multicolumn{5}{|l|}{ Laboratories } \\
\hline Name & $\begin{array}{l}\text { Novogenia/ } \\
\text { Regensburg }\end{array}$ & Kneissler & Scheiber & DATEV \\
\hline $\begin{array}{l}\text { Location } \\
\text { Result summary ** }\end{array}$ & outside county & within county & within county & within city \\
\hline Weekly pools (approx.) & 430 & 36 & 200 & 225 \\
\hline Participants (approx.) & 4300 & 800 & 2300 & 2100 \\
\hline $\begin{array}{l}\text { Positive individual } \\
\text { tests }\end{array}$ & 6 & 0 & 0 & 0 \\
\hline
\end{tabular}

* from https:/ / www.statistikdaten.bayern.de/genesis/online, last assessed 26 September 2021; ${ }^{* *}$ as of 23 July 2021.

Table 2. Peripheral laboratories and test procedures in participating laboratories.

\begin{tabular}{|c|c|c|c|c|}
\hline Test Steps: & $\begin{array}{l}\text { Novogenia/ } \\
\text { Cham }\end{array}$ & $\begin{array}{c}\text { Kneissler/ } \\
\text { Schwandorf }\end{array}$ & $\begin{array}{c}\text { Scheiber/ } \\
\text { Tirschenreuth }\end{array}$ & $\begin{array}{c}\text { DATEV/ } \\
\text { Nuremberg }\end{array}$ \\
\hline Sputolysis & ascorbic acid & ascorbic acid & _- & ascorbic acid \\
\hline RNA isolation & $\begin{array}{c}\text { MagnifiQ RNA buffer } \\
\text { kit (A\&A } \\
\text { Biotechnology) }\end{array}$ & $\begin{array}{l}\text { Foodproof magnetic } \\
\text { preparation Kit VI } \\
\text { (Biotecon) }\end{array}$ & $\begin{array}{l}\text { EchoLUTION Viral } \\
\text { RNA/DNA Swab } \\
\text { (BioECHO) }\end{array}$ & $\begin{array}{c}\text { Lysis: TCEP } \\
\text { (Tris(2-carboxyethyl) } \\
\text { phos-phine } \\
\text { hydrochloride }\end{array}$ \\
\hline qPCR master mix & $\begin{array}{c}\text { FTD }^{\mathrm{TM}} \text { SARS-CoV-2 } \\
\text { (Siemens Healthineers) }\end{array}$ & $\begin{array}{c}\text { SARS-CoV-2 Complete } \\
\text { Kit (Kylt) }\end{array}$ & $\begin{array}{c}\text { VirQ Rapid } \\
\text { SARS-CoV-2 (BAG } \\
\text { Diagnostics) }\end{array}$ & $\begin{array}{l}2 \times \text { Luna Probe } \\
\text { One-Step Reaction Mix } \\
(\mathrm{NEB})\end{array}$ \\
\hline Targeted genes & $\begin{array}{l}\mathrm{N} \text { gene and ORF1ab } \\
\text { region of SARS-CoV-2 }\end{array}$ & $\begin{array}{l}\mathrm{N} \text { gene and } \mathrm{S} \text { gene of } \\
\text { SARS-CoV-2 }\end{array}$ & $\begin{array}{c}\text { RdRP gene and E gene } \\
\text { of SARS-CoV-2 }\end{array}$ & $\begin{array}{l}\text { N1 region of the } \mathrm{N} \\
\text { gene of SARS-CoV-2 }\end{array}$ \\
\hline Extraction control & $\begin{array}{c}\text { equine arteritis virus } \\
(\mathrm{EAV})\end{array}$ & human $ß$-actin gene & RNase P & RNase P \\
\hline PCR cycler & $\begin{array}{l}\text { Quantstudio } 5 \text { (Thermo } \\
\text { Fischer Scientific) }\end{array}$ & $\begin{array}{c}\text { LightCycler96 (Roche), } \\
\text { Stratagene Mx3005p } \\
\text { (Agilent Technologies), } \\
\text { AriaMx (Agilent } \\
\text { Technologies) }\end{array}$ & $\begin{array}{c}\text { CFX } 96 \text { (BioRad), CFX } \\
\text { Opus } 96 \text { (BioRad) }\end{array}$ & $\begin{array}{l}\text { MIC Magnetic } \\
\text { Induction Cycler } \\
\text { (Biozym) }\end{array}$ \\
\hline $\begin{array}{l}\text { Confirmation } \\
\text { method }\end{array}$ & $\begin{array}{l}\text { Initial assay already } \\
\text { targets } 2 \text { genes }\end{array}$ & $\begin{array}{l}\text { Initial assay already } \\
\text { targets } 2 \text { genes }\end{array}$ & $\begin{array}{l}\text { Initial assay already } \\
\text { targets } 2 \text { genes }\end{array}$ & $\begin{array}{l}\mathrm{N} 1 \text { and } \mathrm{N} 2 \text { regions of } \\
\text { the } \mathrm{N} \text { gene of } \\
\text { SARS-CoV-2 }\end{array}$ \\
\hline
\end{tabular}

Despite differences in the set-ups, all laboratories were able to detect positive and negative gargle-based pool samples in ring experiments correctly, although the CT values differed (Table 3). 
Table 3. Results of ring experiments in participating laboratories.

\begin{tabular}{|c|c|c|c|c|c|}
\hline \multicolumn{2}{|c|}{$\begin{array}{l}\text { Blinded } \\
\text { Sample }\end{array}$} & \multirow{2}{*}{$\begin{array}{c}\begin{array}{c}\text { Regensburg/ } \\
\text { Cham * }\end{array} \\
\text { Positive } \\
\text { CT values: } \\
\text { N2 gene: } 31.64 \\
\text { ORF1b gene: } 31.59\end{array}$} & \multirow{2}{*}{$\begin{array}{c}\text { Kneissler/ } \\
\text { Schwandorf } \\
\text { Positive } \\
\text { CT value: } \\
\text { N gene: } 39.3\end{array}$} & \multirow{2}{*}{$\begin{array}{c}\text { Scheiber/ } \\
\text { Tirschenreuth } \\
\text { Positive } \\
\text { CT values: } \\
\text { E gene: } 35.01 \\
\text { RdRP gene: } 35.12\end{array}$} & \multirow{2}{*}{$\begin{array}{c}\begin{array}{c}\text { DATEV/ } \\
\text { City of } \\
\text { Nuremberg }\end{array} \\
\text { Positive } \\
\text { CT value: } \\
\text { N1 gene:33.62 }\end{array}$} \\
\hline $\begin{array}{c}\text { Positive gargle } \\
\text { sample }\end{array}$ & Results test 1 & & & & \\
\hline $\begin{array}{c}\text { Negative gargle } \\
\text { sample }\end{array}$ & & negative & negative & negative & negative \\
\hline $\begin{array}{c}\text { Positive gargle } \\
\text { sample }\end{array}$ & Results test 2 & $\begin{array}{c}\text { Positive } \\
\text { CT values: } \\
\text { N2 gene: } 32.36 \\
\text { ORF1b gene: } 31.9\end{array}$ & $\begin{array}{c}\text { Positive } \\
\text { CT values: } \\
\text { N gene: } 34.87 \\
\text { S gene:33.14 }\end{array}$ & $\begin{array}{c}\text { Positive } \\
\text { CT values: } \\
\text { E gene: } 33.6 \\
\text { RdRP gene: } 36.7\end{array}$ & $\begin{array}{c}\text { Positive } \\
\text { CT value: } \\
\text { N1 gene: } 35.18\end{array}$ \\
\hline $\begin{array}{c}\text { Negative gargle } \\
\text { sample }\end{array}$ & & negative & negative & negative & negative \\
\hline
\end{tabular}

* Novogenia was no longer performing tests in the project at the time of the ring experiments. CT: cycle threshold.

\subsection{IT Solutions for Data Transfer}

Meanwhile, the IT team implemented four different ways of transfering laboratory results into the WICOVIR software electronically, according to the needs of the individual participating laboratories (Figure 2).

First, we implemented an easy to use and flexible data entry system, which allowed manual individual data entry. Furthermore, data exchange using a file exchange protocol based on CSV files was created. In this scenario, the laboratory software would periodically check for the presence of a request file on the WICOVIR server. Once found, the request file is downloaded and parsed and the file itself contains the sample IDs corresponding to the test pools requested. In turn, the laboratory software then uploads the results files to the WICOVIR server, where they are parsed and the values stored to the database. For laboratories that support standardized solutions, such as HL7 or LDT, this data transfer approach was provided. The standardized nature of these formats and protocols helped in the rapid development of these interfaces. However, the need to address the details of each interface and the complexity of these standards diminished to some extent the initial advantage offered. Overall, implementation of four separate interfaces was, however, successfully accomplished by a small team, and a fully operational state was achieved within four weeks, in close collaboration with IT staff from the individual laboratories.

\subsection{Implementation in Different Rural Settings}

On 14 March 2021, the Eastern Bavarian County of Cham (128.094 inhabitants as of $31.12 .2020,1.527 \mathrm{~km}^{2}$ ), which had a seven-day incidence exceeding 200 COVID-19 cases per 100.000 inhabitants at the time, decided to participate in the project. A first pilot test, which included all children willing to participate in the primary schools of the county, was performed successfully on 22 March 2021 with samples received by the laboratory at 9:30 a.m. and pool testing results available at 1:30 p.m. Within the following two weeks, all necessary preparations were made for a regular testing scheme. We note that ethical approval was granted for the inclusion of all children attending the participating schools. After the Easter vacation, all 38 primary schools in the county participated in WICOVIR on a regular basis (Figure 1). Samples were collected from all schools throughout the county by drivers of the local road service teams and processed by the study team in a laboratory of the local hospital in the county. Pools were unpacked from containers, and $1 \mathrm{~mL}$ of the pooled solution was transferred into a microtube (Micronic) under a laboratory hood, then scanned into the WICOVIR software system. The workflow was established with three workers, with one person unpacking, one pipetting, and one registering, so that up to 220 pools were prepared for automated analysis within 75 min at Novogenia 
GmbH laboratory in Eugendorf /Salzburg and, subsequently, also in the central WICOVIR laboratory in Regensburg.

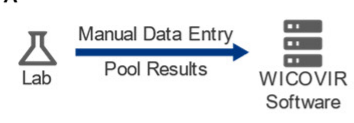

$B$

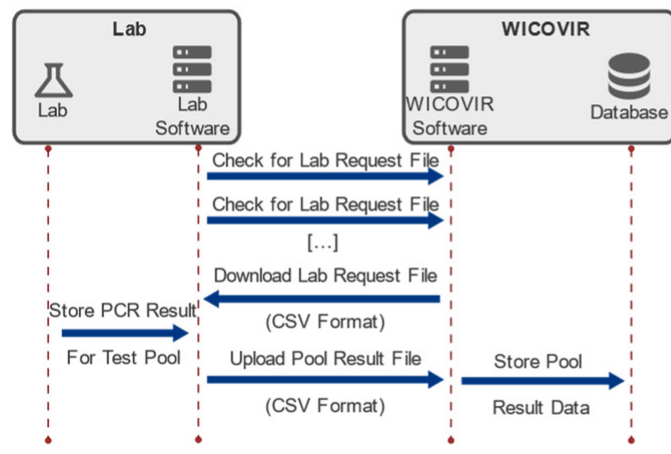

c

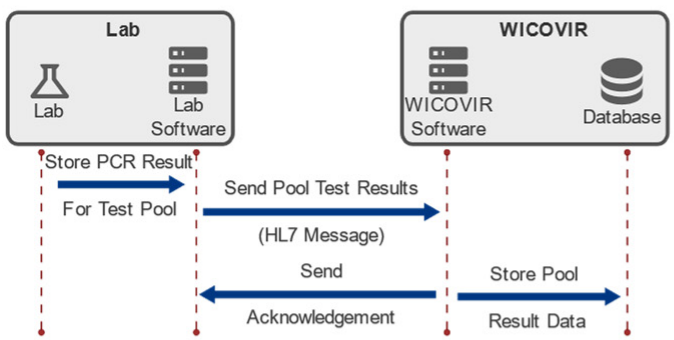

D

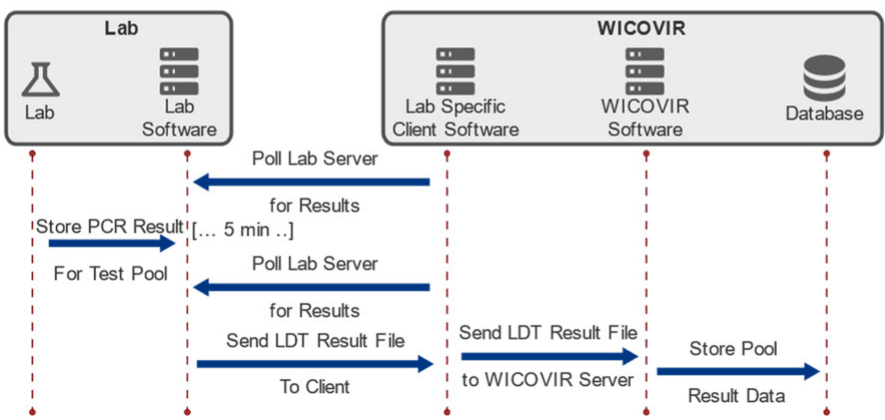

Figure 2. Interfacing with laboratories. Data transfer concepts for the implementation of WICOVIR according to different laboratory set-ups. Four separate interfaces for electronic data exchange between labs and the WICOVIR software have been established. They use different levels of standardization with respect to data formats and protocols ranging from manual entry (A) over exchange of CSV files (B) to HL7 (C) and LDT (D).

Pooling results were available the same evening, and in the case of a positive pool, depooling was performed in the WICOVIR laboratory in Regensburg the next morning. The local public health office informed the schools and families about positive results on the evening of the test, and a quarantine was implemented until the positive individual was identified the following morning. Within the first four weeks after implementation of the testing program, 15,724 tests were performed, identifying three positive cases. Three weeks into the project, testing was further extended to an additional 3000 children returning to primary schools after lockdown, and a further three positive cases were detected.

The rural County of Tirschenreuth was a COVID-19 hotspot in the first wave of the pandemic in Germany in the spring of 2020, and showed a high incidence of infections again 
early in the second wave in the winter of 2020-2021. However, through intensive voluntary testing introduced early on in 2021 and strict infection protection measures, as well as the participation in scientific evaluation of the previous breakouts, Tirschenreuth achieved a continuously low incidence of new COVID-19 cases early in 2021. Participation in the WICOVIR project was thus a logical next step. Overall, eight schools, with 2280 students and teachers, participated in the project. The program was initiated on 22 April 2021, and after clearing administrative issues and financing, regular testing started on 10 May 2021. For testing in Tirschenreuth county, a local laboratory was available, substantially reducing transport time to less than one hour. WICOVIR was also set up in the rural county of Schwandorf, in which testing was implemented in a selection of primary and secondary schools using a laboratory in the county. Due to restrictions in financing, however, only seven schools were able to participate in the testing there.

\subsection{Implementation in an Urban Setting}

In the city of Nuremberg, a large company took the initiative to establish their own testing laboratory in close cooperation with the WICOVIR Erlangen central laboratory. A laboratory container was established on the company site for testing of employees, and resources were donated by the company for school testing. The container was delivered to the site on 06 April 2021. The first laboratory employees started on 12 April 2021, and after a test phase under the supervision of the Erlangen laboratory, regular testing commenced on 15 April 2021. Within the first three months, 1738 pools, including 18,671 individuals, were tested. The number of schools in which testing took place increased to 16 over this time period.

\section{Discussion}

After establishment of WICOVIR facilities for testing for SARS-CoV-2 infection in schools in two large, centrally located scientific laboratories in Erlangen and Regensburg, we show here how the WIOCIVR protocol can be successfully implemented within four weeks in rural and urban regions with minimal effort, making use of pre-existing logistical structures and laboratory testing facilities or by creating new regional collaborations. Quality of testing and comparability of test results were assured through ring experiments. A common databank structure allowed for a shared but anonymous analysis of study results and quality control in real time. Close collaboration with public health officials on site, the school administration, and local authorities were keys for success.

The overall technical feasibility of gargle-based pool testing in a pandemic has been shown repeatedly [10]. In a previous feasibility study, we established that implementing an algorithm that required participating families to remember to access a web-based app on a regular basis, to enable selection of participants for each testing round, based on an algorithm to maximize the probability of detecting a positive case, was a rate-limiting step [7]. The inclusion of all pupils attending the participating schools in the WICOVIR program, made possible by the reduction in testing costs, enabled implementation of a successful monitoring program, in which chains of infection were broken before the emergence of symptoms [10]. The question remained, however, whether such an approach could be implemented outside of a clearly defined study setting, such as on a university campus or within a small test area, and, if applicable, which resources and set-ups would be necessary for a rapid implementation.

Overall, we found that regulatory issues were the most cumbersome and timeconsuming aspect to be overcome in the process of establishing such a test program. Once all data protection issues were cleared centrally with the Ministry of Education, all other steps in the implementation process on site were comparatively easy. Whenever local authorities and school boards were convinced that pool testing offered an advantage for schools and pupils, their support was overwhelming. Major concerns at the start were the reliability of gargling at home, additional restraints/workload for the schools, time until test results are communicated, and logistics (supply and transport). 
We addressed all general issues extensively in our previous publication, and we showed that these did not depend on the region where the test system was implemented [10]. We demonstrated that the test system is safe, as it protected participating schools from outbreaks; efficient, as it successfully led to the identification of a positive individual within a day; and cost-effective, as it reduced the costs per tested participant to less than $€ 1$ in the study setting. In contrast, the issues of documentation and communication of results may be affected by the respective regional laboratory set-ups. However, our IT team developed solutions for all situations we encountered in the participating laboratories, and these are applicable to almost every other laboratory set-up $[6,7,10]$. Once the software was established, information flow pertaining to schools, health officers, and test participants was swift. Depooling results were always communicated to health authorities and participants within a day. To make timely use of the test data by health officers is important in rendering the test system successful in preventing disease spread. Rapid testing without a similarly swift reaction of health officials to contain transmission is of no value.

Supply logistics with test equipment (plastic ware) were organized centrally to reduce costs and guarantee the availability of plastic ware in times of material shortages and quadrupling prices, which were relevant even in an industrialized country such as Germany. The insufficiency of supplies emerged as a substantial limiting factor for testing, and resource-sparing procedures are thus key to the success of such a testing system. In our system, tubes for gargling were personalized and reused by the test participants and laboratory procedures were designed to use a maximum of only two pipette tips per pool sample.

Transport logistics of the gargle-based pool samples in large counties presented a major concern at the beginning of the project. A range of solutions were developed to solve this issue. For example, in Cham County, which is a large region, the schools were grouped into four routes, with a driver for each. The driver picked up samples in the morning, and the first batch was delivered to a central collection point in the county (laboratory of the local hospital) by approximately 8:30 a.m. Pipetting could then start, while samples from farther, more remote schools, were delivered later (Figure 1, small graph). In Cham, drivers were recruited from the county workforce, but in other instances, members of the families whose children attended the schools volunteered to provide this transportation. The lengths of individual routes were limited in order to avoid delays in the processing of the samples. Transport logistics are sensitive to external disruption such as the traffic situation or weather conditions and require adequate human resources and detailed planning.

At the central collection point in the laboratory of the local hospital, pool-samples were registered in the documentation system and pipetted into matrix-tubes for automated processing in the testing laboratory, dramatically reducing the volume for transport (by a factor of 100-fold) and allowing a swift handling of the samples in the testing laboratory. (As samples had already been registered in the test system, no further documentation was required in the testing laboratory.) For this step, a laminar air flow, a vortex, a pipette, and a documentation system (barcode scanner and laptop) were needed. On average, 200 pools were transferred into matrix-tubes and documented within $75 \mathrm{~min}$, before they were sent on to the testing laboratory. This transfer step relies on manual work and is a rate-limiting step in the automatization of the process.

In our opinion, having a test laboratory within the county or region offers a crucial advantage, as it reduces transport time (and thus time until results are available to participants). In addition, performing PCR testing locally was perceived by the study team, in communication with the schools and families, to strengthen the feeling of selfempowerment within the community in fighting the pandemic, resulting in the establishment of a partnership based on trust between the test laboratory and the local community. However, as shown in the set-up for Cham, such a local laboratory is not a prerequisite for a successful implementation. Nonetheless, when depooling is necessary for positive pools, long transport times may lead to the availability of depooling results only on the 
following day, which can critically delay identification of positive individuals and the timely implementation of protective measures to break an infection chain.

We conclude that even without a local laboratory in the county, testing in schools using the WICOVIR protocol can be achieved successfully within less than four weeks, and logistical challenges can be overcome. With the WICOVIR setup, testing in schools is easy to set up, reliable, and low in cost, leading to timely results which were generally available on the same day or within a maximum of $24 \mathrm{~h}$.

Author Contributions: Conceptualization: M.G., P.S., A.A., T.W., A.B., M.K. (Michael Kabesch) Methodology: P.K.: M.A., P.S., E.C., J.S., A.K., D.W., G.J., M.H., A.A., T.W., A.B., M.K. (Michael Kabesch) Software: C.B., J.N., P.P., T.W. Validation: M.G., P.K., M.A., J.S., A.K., D.W., A.A., A.B., M.K. (Michael Kabesch), C.M.S.-R. Formal analysis: A.A.: T.W., A.B., M.K. (Michael Kabesch) Investigation: P.K., M.G., M.A., P.S., E.C., K.S., C.K., J.-T.B., S.R., C.R., A.M., C.F., S.G., M.B., M.K. (Maike Konrad) Resources: J.S., A.K., D.W., A.A., T.W., A.B., M.K. (Michael Kabesch) Data Curation: M.G., A.B., M.K. (Michael Kabesch) Writing-Original Draft Prep.: P.K., M.G., M.A., P.P. Writing-Review \& Editing: A.A., T.W., A.B., M.K. (Michael Kabesch), C.M.S.-R. Visualization: P.P., M.K. (Michael Kabesch) Supervision: P.S., J.S., A.K., D.W., H.B.-D., G.J., M.H., A.A., A.B., M.K. (Michael Kabesch) Project Administration: P.S., L.P., H.B.-D., A.B., M.K. (Michael Kabesch) Funding Acquisition: L.P., T.W., A.B., M.K. (Michael Kabesch). All authors have read and agreed to the published version of the manuscript.

Funding: This work was supported by the Bavarian State Ministry of Health (Grant "WICOVIR") and the Bavarian State Ministry of Science (Grant "STACADO").

Institutional Review Board Statement: The study was conducted according to the guidelines of the Declaration of Helsinki, and approved by the Ethics Committee of the University of Regensburg (protocol code 21-2240_2-101).

Informed Consent Statement: Informed consent was obtained from all subjects involved in the study.

Data Availability Statement: The data generated for this publication have been included in the current manuscript.

Acknowledgments: We are grateful to all test participants and parents who helped us to improve our system further, the students and teachers for participating in the tests and many people that did much more for their community than what their job description may suggest. Specifically, we want to thank Martin Ritt for organizing the general setup in Cham and solving all problems locally before they became problems, Karl Utz and Rudolf Hoffmann from whom we learned how to organize schools effectively in the project, Thomas Böhm and his team who solved transport logistics with unprecedented speed, reliability and smiles, Beate Gschwendner and Fabian Müller who supported the use of the laboratory of the Cham hospital, Markus Zapf and Regina Kestel and Viktoria Schmalhofer who were key for organizing testing in their counties, and Sandra Merkinger who was a great partner at Novogenia to make things possible right from the start.

Conflicts of Interest: All authors except those belonging to commercial laboratories (Kneissler, Maganamed Novogenia, Scheiber) declare that they have no competing financial or personal interests. Authors belonging to commercial entities did not influence the content of this publication but provided service for set-up and testing in the project.

\section{References}

1. Kamidani, S.; Rostad, C.A.; Anderson, E.J. COVID-19 Vaccine Development: A Pediatric Perspective. Curr. Opin. Pediatr. 2021, 33, 144-151. [CrossRef] [PubMed]

2. Osterman, A.; Baldauf, H.-M.; Eletreby, M.; Wettengel, J.M.; Afridi, S.Q.; Fuchs, T.; Holzmann, E.; Maier, A.; Döring, J.; Grzimek-Koschewa, N.; et al. Evaluation of Two Rapid Antigen Tests to Detect SARS-CoV-2 in a Hospital Setting. Med. Microbiol. Immunol. 2021, 210, 65-72. [CrossRef] [PubMed]

3. Scohy, A.; Anantharajah, A.; Bodéus, M.; Kabamba-Mukadi, B.; Verroken, A.; Rodriguez-Villalobos, H. Low Performance of Rapid Antigen Detection Test as Frontline Testing for COVID-19 Diagnosis. J. Clin. Virol. 2020, 129, 104455. [CrossRef] [PubMed]

4. Rafiei, Y.; Mello, M.M. The Missing Piece-SARS-CoV-2 Testing and School Reopening. N. Engl. J. Med. 2020, 383, e126. [CrossRef] [PubMed]

5. Paltiel, A.D.; Zheng, A.; Walensky, R.P. Assessment of SARS-CoV-2 Screening Strategies to Permit the Safe Reopening of College Campuses in the United States. JAMA Netw. Open. 2020, 3, e2016818. [CrossRef] [PubMed] 
6. Sweeney-Reed, C.M.; Wolff, D.; Niggel, J.; Kabesch, M.; Apfelbacher, C. Pool Testing as a Strategy for Prevention of SARS-CoV-2 Outbreaks in Schools: Protocol for a Feasibility Study. JMIR Res. Protoc. 2021, 10, e28673. [CrossRef] [PubMed]

7. Sweeney-Reed, C.M.; Wolff, D.; Hörnschemeyer, S.; Faßhauer, H.; Haase, A.; Schomburg, D.; Niggel, J.; Kabesch, M.; Apfelbacher, C. Feasibility of a surveillance programme based on gargle samples and pool testing to prevent SARS-CoV-2 outbreaks in schools. Sci. Rep. 2021, 11, 19521. [CrossRef] [PubMed]

8. Cibali, E.; Wenzel, J.J.; Gruber, R.; Ambrosch, A. Pooling for SARS-CoV-2-Testing: Comparison of Three Commercially Available RT-QPCR Kits in an Experimental Approach. Clin. Chem. Lab. Med. 2021, 59, e243-e245. [CrossRef] [PubMed]

9. Hitzenbichler, F.; Bauernfeind, S.; Salzberger, B.; Schmidt, B.; Wenzel, J.J. Comparison of Throat Washings, Nasopharyngeal Swabs and Oropharyngeal Swabs for Detection of SARS-CoV-2. Viruses 2021, 13, 653. [CrossRef] [PubMed]

10. Kheiroddin, P.; Schöberl, P.; Althammer, M.; Cibali, E.; Würfel, T.; Wein, H.; Kulawi, B.; Buntrock-Döpke, H.; Weigl, E.; Gran, S.; et al. Results of the WICOVIR Gargle Pool PCR Testing in German School Children Based on the First 100,000 Tests. Front. Pediatr. 2021, 9, 721518. [CrossRef] [PubMed] 